\title{
O Enfrentamento da Morte e do Morrer na Formação de Acadêmicos de Medicina
}

\author{
Dealing with Death and Dying in \\ Undergraduate Medical Training
}

\author{
Nára Selaimen G. Azeredo ${ }^{I}$ \\ Cristianne Famer Rochall \\ Paulo Roberto Antonacci Carvalho
}

\section{PALAVRAS-CHAVE \\ - Morte. \\ - Atitude frente à Morte. \\ - Limite Terapêutico. \\ - Educação Médica. \\ - Currículo.}

\section{KEYWORDS}

- Death.

- Confronting Death Attitude.

- Therapeutic Limit.

- Medical Education.

- Curriculum.

Recebido em:14/09/2009

Reencaminhado em: 26/04/2010

Reencaminhado em: 11/02/2010

Aprovado em: 30/05/2010

REVISTA BRASIIEIRA DE EDUCAÇ̄̃o MÉDICA
${ }^{I}$ Hospital Nossa Senhora da Conceição, Porto Alegre, RS, Brasil.

"I Universidade Federal do Rio Grande do Sul, Porto Alegre, RS, Brasil.

\section{RESUMO}

Este estudo teve como objetivo conhecer como os acadêmicos de Medicina percebem que a graduação os prepara para o enfrentamento da morte, bem como compreender o que significa para estes alunos o enfrentamento da morte e do morrer em sua prática formativa. Trata-se de estudo qualitativo de caráter exploratório e descritivo. Foram utilizadas, como técnica de coleta de dados, entrevistas semiestruturadas com cinco estudantes de Medicina que já estão no internato, analisadas a partir da técnica de Análise de Conteúdo de Bardin. Os resultados aqui apresentados se referem apenas a uma das categorias de análise criadas para o estudo - "sentir-se preparado frente à morte e ao morrer". Como principal conclusão deste estudo, em relação a esta categoria, podemos citar o sentimento de não preparação assinalado pelos acadêmicos entrevistados, sobretudo em função da necessária objetividade e do distanciamento "profissional" do paciente que está morrendo.

This study focuses on how medical students perceive the way that undergraduate medical education prepares them to deal with death, and to understand what it means to these students to deal with death and dying in their training. This was a qualitative, exploratory, and descriptive study. The data collection used semi-structured interviews with five medical students that were already in their internship (the final stage of undergraduate training in Brazil), analyzed on the basis of Bardin's content analysis technique. The findings presented here refer to only one of the analytical categories for the study - "feeling prepared in the face of death and dying". The study's principal finding in this category is a feeling of unpreparedness, highlighted by the interviewees, especially as a function of the necessary objectivity and "professional" distancing from the dying patient. 


\section{INTRODUÇÃO}

A presença da morte no cotidiano dos profissionais de saúde é uma constante. Ela também se faz constante nas vivências e no aprendizado dos acadêmicos de Medicina que passam pelos hospitais. Por esta razão, identificar o significado da morte e do morrer, bem como de que maneira o acadêmico de Medicina elabora a sua relação com o limite terapêutico, parece ser uma necessidade.

Da mesma forma, é verdadeiro que a morte e o morrer são temas frequentemente discutidos pelos profissionais da saúde. Contudo, também é fato que muitas destas discussões estão perpassadas por questões relacionadas a como realizar procedimentos corretos, técnicas assépticas, administrar medicamentos adequados e o motivo pelo qual as terapêuticas fracassam diante da morte. Poucos são os espaços que questionam os sentimentos e as percepções destes profissionais diante da morte.

Atualmente, as mortes, em sua maioria, ocorrem em hospitais empenhados no processo de cura. O paciente cuja doença não pode ser curada é visto como um fracasso para os profissionais e para estas instituições. O que importa é vencer a doença a qualquer custo. O objeto de trabalho do médico, em algumas situações, parece que passou a ser a doença; logo, vencer a morte é vencer um adversário.

Além disto, historicamente, ninguém gosta de falar sobre a morte, sobre o fim. Este assunto atemoriza, mesmo sendo uma verdade inabalável. Esta pesquisa nasce, portanto, de uma preocupação de como os profissionais lidam com estes sentimentos tão intensos. Por conseguinte, visa a examinar como os acadêmicos percebem que estão sendo preparados e aprendendo a conviver com a morte e com o morrer dentro da formação médica.

\section{OBJETIVOS}

Conhecer como os acadêmicos de Medicina percebem que a graduação os prepara para o enfrentamento da morte, bem como compreender o que significa para estes alunos o enfrentamento da morte e do morrer em sua prática formativa.

\section{MÉTODO}

Este artigo é produto da pesquisa desenvolvida junto ao Programa de Pós-Graduação em Pediatria da Universidade Federal do Rio Grande do Sul e procurou dar voz aos atores que dela participaram, nomeadamente os estudantes de Medicina. Norteado por um paradigma qualitativo, o estudo teve caráter exploratório e descritivo1, já que se buscou realizar um diagnóstico da situação relativamente aos estudantes do internato do curso de Medicina e suas percepções e seus conhecimentos frente à morte e ao morrer. A técnica de coleta de dados escolhida, nesta fase da pesquisa, foi a de entrevistas semiestruturadas $^{2}$, conduzidas pela investigadora principal, no período de julho a dezembro de 2006, após prévia aprovação do Comitê de Ética em Pesquisa do Hospital de Clínicas de Porto Alegre.

Tratando-se de um estudo qualitativo, utilizou-se uma amostra intencional, não-probabilística. $\mathrm{O}$ recrutamento dos participantes seguiu a regra de maximizar a diversidade da amostra, tentando assegurar a pertinência e não a aleatoriedade. Foram entrevistados cinco estudantes de Medicina que já estavam no período de internato, ou seja, realizando atividades práticas no campo hospitalar. Antes do início das entrevistas, os participantes assinaram o Termo de Consentimento Livre e Esclarecido.

As entrevistas foram todas gravadas e transcritas em sua totalidade, de acordo com regras anteriormente definidas, para garantir a uniformização das mesmas. De comum acordo com os entrevistados, foram usados codinomes escolhidos pelos próprios entrevistados, a fim de poder identificar suas respostas, observando-se, no entanto, que os dados pessoais, durante e após a realização das entrevistas, fossem mantidos em absoluto anonimato.

Para $\mathrm{Minayo}^{2}$, as entrevistas têm um sentido amplo de comunicação verbal, sendo que as semiestruturadas fazem uma combinação de perguntas que possibilita ao entrevistado expor o tema proposto sem condições prefixadas pelo pesquisador.

Os textos obtidos após a transcrição das entrevistas foram analisados a partir da técnica de Análise de Conteúdo de Bar$\operatorname{din}^{3}$, através da codificação e interpretação, buscando compreender as informações e os dados que se apresentam nas mensagens analisadas.

Para Bardin³, a Análise de Conteúdo é "um conjunto de técnicas de análise das comunicações" (p. 42). Não se trata, segundo ela, de um instrumento único, mas de um leque de apetrechos, adaptável de acordo com a disparidade de documentos e objetivos dos investigadores. A Análise de Conteúdo, portanto, é uma construção que tem como ponto de partida a realidade concreta dos sujeitos, assim como sua história. Para a sua realização, decorrem três diferentes fases: a pré-análise (em que se organiza o material empírico, a fim de sistematizar as ideias iniciais e criar as categorias de análise); a exploração do material (em que, após a definição das categorias de análise, são realizadas as operações de busca e separação do material empírico); e, por fim, a fase de tratamento dos resultados obtidos e sua interpretação (em que os "materiais brutos" são tratados de maneira a serem significativos e válidos aos interesses da pesquisa realizada). 
As diferentes respostas dos entrevistados às questões apresentadas foram agrupadas em categorias discursivas de acordo com a regularidade com que determinados elementos apareceram e se repetiram nas entrevistas, e também de acordo com a importância dos mesmos para o alcance dos objetivos da pesquisa. Inicialmente, foram criadas quatro categorias de análise: "a escolha da Medicina", "o primeiro contato com a morte", "o limite terapêutico" e "sentir-se preparado frente à morte e ao morrer". Neste texto, será apresentada a análise dos dados obtidos em uma das categorias definidas, ou seja, aquela relacionada ao "sentir-se preparado frente à morte e ao morrer".

\section{SENTIR-SE PREPARADO FRENTE À MORTE E AO MORRER}

Conhecer o quanto os estudantes de Medicina estão preparados em relação à temática da morte e do morrer é poder contextualizar o universo de valores e atitudes em que estão inseridos ${ }^{4}$. No que diz respeito à formação médica, alguns autores ${ }^{5,6}$ afirmam que existe um treinamento que, muitas vezes, acaba afastando a emoção do aluno diante do paciente. Desta forma, o aluno passa a reconhecer no paciente a doença e não a pessoa.

De acordo com os entrevistados, esta concepção de que a morte deve ser compreendida de forma objetiva parece ser dominante:

“Olha, desde o início da faculdade, a gente é ensinada a olhar objetivamente o paciente, tentando separar qualquer possível relação que se forme tanto entre o paciente $e$ o médico, como médico e o paciente." (Fragmento da entrevista de a5, grifo nosso)

O ocultamento da morte, na maioria dos currículos médicos e na formação médica, passa pelo fato de que só os saberes biológicos são tidos como saberes verdadeiros ${ }^{7}$. Um dos acadêmicos entrevistados nos diz:

"A vida é um ciclo. Tem hora que acaba, e acaba [...] É o final do ciclo" (Fragmento da entrevista a2).

Muitos autores afirmam que, se a morte é parte do ciclo da vida humana, então, cuidar do corpo que está morrendo deve ser parte integral dos objetivos da Medicina, assim como acreditam que a exclusão dos temas da morte e do morrer, dentro da formação médica, é intencional e está relacionada com o fato de os médicos não se envolverem com o que acontece com os pacientes ${ }^{8,9,10}$ Porém, fica claro, nas falas dos alunos entrevistados, o não reconhecimento desta habilidade como uma competência na formação médica, assim como a busca de uma relação mais equilibrada por parte dos alunos, com menos impessoalidade e mais humanização na assistência aos pacientes:

\section{“É tudo muito rápido e tu continuas. Tu não tens tempo para parar. O que está acontecendo? Ah! Morreu? Ah! Tudo bem! O outro paciente está precisando de tal coisa, vai lá! [...]. É uma ideia assim, sabe? Na verdade, é pouco trabalhado o tema morte na faculdade. Pouco dito, pouco conversado, en- fim." (Fragmento da entrevista de a3)}

É preciso ficar alerta para aquilo que os próprios entrevistados julgam ser o "momento" mais adequado para trabalhar academicamente o tema da morte. Segundo eles, não se trata de inserir mais uma disciplina teórica sobre o assunto:

"Uma aula teórica sobre a morte é uma coisa. Na hora que acontece, é diferente. A gente não está preparada para isto. Falta muita coisa. A gente aprende na hora em que vai ter que dar a notícia: 'Vai! Fala!'" (Fragmento da entrevista de a1, grifo nosso)

Outra entrevistada reafirma a importância de que a formação não ocorra apenas teoricamente:

"Atividade teórica eu acho que não. A gente teve contato com isto [...]. Quando eu tive aula de morte, não tinha acontecido comigo ainda. Não fazia parte da minha realidade; o meu paciente não tinha morrido ainda. Ainda é distante. Eu acho que seria interessante se a gente tivesse uma porta aberta. Para que, quando acontecesse, a gente pudesse: 'Ah, vem aqui conversar'. Tem uma situação? Então, tu tens alguém para discutir isso contigo [...]. Nunca acontece como a gente aprendeu na teoria." (Fragmento da entrevista de a3, grifo nosso)

A ruptura na comunicação entre médico e paciente (e dos médicos entre si) verificada através da atitude de não falar da doença (e da morte) e que, posteriormente, vai contaminando todos os assuntos condena o paciente ao isolamento ${ }^{8}$. Se, por um lado, nunca antes as pessoas morreram de forma tão silenciosa e higiênica como em nossa sociedade, por outro lado, nunca morreram em condições tão propícias à solidão. Um dos entrevistados externa esta preocupação da seguinte maneira:

"Com o avançar da Medicina, com toda a tecnologia [...], a gente acaba tendo muito uma visão de vida, vida, vida, e não 
entende a morte como parte do ciclo vital." (Fragmento da entrevista de a1)

Há até bem pouco tempo, o homem enfrentava a morte em casa. Estavam junto a ele a família e os amigos. Seus desejos e suas vontades eram respeitados, pois lhe era permitido expressá-los. Era raro o doente ser encaminhado ao hospital para morrer ${ }^{11}$. Um dos entrevistados alerta sobre esta situação:

"Pelas coisas que já li, antigamente, a morte era mais natural. Era mais aceita. A única certeza que temos é que a morte é certa. Acredito que o sentido da evolução da vida é a morte." (Fragmento da entrevista de a4)

Talvez a aceleração do processo de interdição da morte esteja associada ao deslocamento do local da morte, pois já não se morre em casa, entre os seus. Assim, na casa, não existe mais a emoção e a perturbação da morte. Em geral, o homem morre sozinho, longe de seus familiares, na solidão de um leito hospitalar.

O hospital passa a ser o novo local para a morte e dá um sentido novo ao ato de morrer ${ }^{11}$. A função do hospital contemporâneo consiste em recuperar a força de trabalho e, quando isto não é possível, em acolher a morte. A técnica se encontra impregnada na estrutura e na organização do hospital $^{12}$. A função do hospital contemporâneo consiste em recuperar a força de trabalho e, quando isto não é possível, em acolher a morte. A técnica se encontra impregnada na estrutura e na organização do hospital ${ }^{13}$. O médico, ainda que seja o profissional símbolo da instituição, passou a ter que dividir poder com outros profissionais de saúde, e a clientela passou a incluir portadores de todos os tipos de enfermidades, físicas ou mentais. Ao se transformar o hospital no local onde as pessoas adoecem e morrem, as questões inerentes a este ato, antes compartilhadas socialmente - pois a morte era domiciliar —, ficam restritas ao âmbito hospitalar. Essa transferência do local onde se morre vem sendo vivenciada de forma rotineira pelos profissionais que lidam com o paciente que está morrendo. No meio médico, não se pode pensar em morte, pois ela não é vista como um desenlace possível, mesmo naqueles casos em que esteja claro que a morte é inevitável:

“Uma das coisas que fico pensando é: o que significa a morte? Por que esta pessoa está morrendo? O que a morte significa para quem está morrendo? Muitas vezes, é o descanso. Aquilo que a pessoa está pedindo, sabe? E o que a morte significa para a gente? A morte é difícil de lidar, porque é a gente que está aqui. É a gente que está sofrendo. É a gente que vai ter que elaborar a ausência da pessoa. E tentar tocar adiante." (Fragmento da entrevista de a1)

A negação da morte coloca o médico numa situação ilusória de onipotência que o protegeria de seus temores e ansiedades. Para defender-se destas situações, extremamente angustiantes e difíceis, os profissionais que lidam com a morte muitas vezes se isolam e se fragmentam. No entanto, ao tentarem fugir da morte, perdem o contato com algo que também faz parte de sua formação ${ }^{14}$. Da mesma forma como a onipotência e o poder de cura são idealizados, também são alienantes, no que se refere tanto à perda como à inevitabilidade da morte:

\footnotetext{
"Muitas vezes, o médico não tem limite, 'até aonde eu vou?'. E a pessoa só piorando [...] Tu estás trazendo mais sofrimento para a pessoa e para a família [...]. Muitas vezes, os médicos se sentem seres superiores a ponto de achar que conseguem reverter situações irreversíveis [...]." (Fragmento da entrevista de a4)
}

Estes fatores impulsionam cada vez mais o estudante e o médico a criarem falsas expectativas e ilusões em relação à sua capacidade de prevenir situações inevitáveis, promovendo enormes frustrações e sensações de impotência quando confrontados com a realidade. Isso poderia ser amenizado se tais expectativas deixassem de ser estimuladas durante a formação médica e fossem mais enfaticamente discutidas e analisadas ${ }^{15}$.

A consciência de se saber mortal, como um atributo específico do homem, determina a organização de seu modo de viver, e a sociedade organiza seu funcionamento em torno da morte. A espécie humana é a única para a qual a morte está presente ao longo da vida. Para o homem, existe o ritual da morte, do funeral, a fé na sobrevivência ou no renascimento dos mortos, fazendo da morte o traço mais cultural do homem. Além disto, o medo que ele tem da morte se deve a que ela constantemente o põe frente a frente com sua vulnerabilidade $^{16}$.

\footnotetext{
"A questão com a qual eu me deparei na Faculdade é com a nossa vulnerabilidade. A fragilidade do ser humano. E toda essa questão de tu poderes estar bem e, dali a pouco, tu descobres uma doença grave e avançada [...]." (Fragmento da entrevista de a1)
}

Além disto, entre o médico e o paciente pode se estabelecer uma relação de ilusão, quando, por um lado, o doente acredita nessa pessoa poderosa que poderá salvá-la de todo o mal; e, por outro lado, o médico toma para si esse poder de resolver todas as necessidades que lhe são solicitadas pelo paciente ${ }^{13}$, 
pois, como afirma um dos entrevistados, "o profissional da Medicina tem uma banalização da morte, que eu acho que é um mecanismo de defesa" (Fragmento da entrevista de a2). É outro alerta para os riscos desta incomensurável tentativa de salvação:

“[...] Então [os médicos] investem continuamente até sabe lá onde. A gente, muitas vezes, esquece do paciente, da vontade do paciente. E muitos médicos pensam na vaidade de não deixar morrer. Se tu continuares investindo, muitas vezes, não trará benefício nenhum. Tu estás só piorando a situação. Tu estás fazendo distanásia". (Fragmento da entrevista de a4)

O avanço em todos os campos dos saberes é notório e indiscutível. Contudo, por maiores que tenham sido os avanços tecnológicos, a morte não parece ter ganhado mais dignidade ou mais paz. Cuidar dignamente de uma pessoa que está morrendo em um contexto clínico significa respeitar a integridade da pessoa.

O conhecimento biológico e as destrezas tecnológicas não deveriam servir para um morrer mais problemático: difícil de prever, mais difícil ainda de lidar, fonte de complicados dilemas éticos e escolhas dificílimas, geradoras de angústia, ambivalência e incerteza ${ }^{10}$ :

"Tem gente que quer investir, investir, investir no paciente para sobreviver, e fica muito mal se a pessoa acaba falecendo. Só que o problema que eu acho não é o limite terapêutico. Assim, de ter ou não ter limite terapêutico. É como decidir esse limite [....]." (Fragmento da entrevista de a2)

O sofrimento no fim da vida é um desafio que se apresenta à Medicina nesta era tecnológica. O processo de morrer traz à tona a questão sobre qual aspecto da vida do paciente deve ser priorizado: a qualidade ou a quantidade de vida. A ideia de viver deveria estar condicionada à ideia de bem-estar, de bem-querer. Não basta ter uma boa Medicina para que se tenha uma boa morte. A boa morte deveria estar acompanhada por uma integração entre os princípios religiosos, morais e terapêuticos, dando àquele que está morrendo um cuidado respeitoso com suas crenças e valores. A boa morte deve garantir o sentido da vida e da existência, para que a morte seja um ato de cuidado. Quando o médico se priva de suas emoções, usando como escudo uma pretensa neutralidade científica, o paciente é, muitas vezes, transformado em objeto. Desta forma, seu corpo passa a ser considerado um meio através do qual se podem observar fenômenos científicos ${ }^{17}$. Ele, paciente, deixa de ser considerado sujeito de sua vida e de sua morte:
"Tem horas que eu acho que a pessoa merece morrer, no sentido de que vai ser um descanso para ela. Vai ser uma coisa boa no final das contas, porque não vai ter um sofrimento tão grande, sabe?" (Fragmento da entrevista de a3, grifos dos autores)

"[...] Mas sei também que o que não é vida para mim pode ser para o outro. Prolongar a vida quando não se tem mais nada a oferecer [...] é uma evolução, é uma parte da vida. Eu considero a morte como uma parte da vida." (Fragmento da entrevista de a4, grifo nosso)

Outro entrevistado relaciona esta dificuldade com a rotina do cotidiano hospitalar, que não permite que se "viva" a morte com o tempo que ela requer:

"Eu acho que seria interessante discutir mais sobre isso nas próprias equipes, entende? Quando um paciente morre, o que se faz? Quando um paciente morrer, discutir: o paciente morreu? O que aconteceu? Discutir o caso no round [...] Acho que seria mais proveitoso, ao invés de 'morreu, saiu da lista. Continuamos a vida!'. Na relação médico-paciente, acho que seria muito interessante falar disso." (Fragmento da entrevista de a2)

A experiência da morte não é vivenciada apenas pelos profissionais da área da saúde: é também vivenciada pelos estudantes que têm como seu objeto de estudo o ser humano $^{8,17,18}$. Por este motivo, eles se defrontam cotidianamente com a doença, com a dor e com a morte. Dentro do hospital, o auxílio da tecnologia também faz parte deste aprendizado diário, em que formulam e reformulam seus conteúdos e suas práticas. Todo esse conjunto de experiências diárias pode tornar latentes, para os alunos, seus sentimentos de impotência diante do não solucionável.

"Eu não só tive que me preparar para perder a minha paciente, que não é uma coisa muito interessante, tu perderes, tu falhares como médico. E também tive que preparar a família. Eu não tenho o tempo para me preparar; eu tenho que preparar a família, depois eu vejo o que acontece comigo. Como eu coloco, eu tento dividir dois lados." (Fragmento da entrevista de a5)

Através do estudo da morte, o aluno pode perceber o desenvolvimento da pessoa como um todo. Sendo assim, a morte poderá ser entendida como uma etapa do processo do desenvolvimento humano. Assim, pode tornar-se um instrumento para pensar a pessoa, o humano e não somente a doença: 
"Eu acho que o limite terapêutico é muito pouco discutido na faculdade. Nossa medicina é muito voltada para a cura. Algumas vezes, continuar insistindo com intervenções e tratamento não seria vantajoso para o paciente. Eu acho que tem que se estudar mais. Tem que ter protocolos para isso. Para se ver até aonde se vai, até aonde não se vai." (Fragmento da entrevista de a2, grifo nosso)

Para Novaes e Trindade ${ }^{19}$, o contato do estudante de Medicina com a morte não pode ser reduzido somente à dissecação de cadáveres em atividades de anatomia. Os autores alertam que "este momento, quase como um rito de passagem em escolas tradicionais, marca sobremaneira a futura postura do estudante que parece aprender e adotar uma postura de maior distanciamento com a condição humana, já que o foco é unicamente a aprendizagem da anatomia humana" (p. 75).

A perda da humanização e da integralidade deixa transparecer a dicotomia entre saúde e doença, entre prevenção e assistência. A dor, a aflição, o sofrimento e a morte não se incluem na detecção das patologias e em sua prevenção, exceto pelo olhar biológico do corpo humano. A humanização e a integralidade parecem seguir fora do eixo estrutural da formação médica. Discutir temas como medo, sofrimento e morte parece não ser um foco central na formação dos profissionais da saúde ${ }^{20}$.

\section{"[...] Em termos acadêmicos, eu não acho que a faculdade te prepara para isso. Eu acho que eles te põem em contato com isso, mas tu não tens nenhuma orientação, a faculdade não te dá nenhuma base. Eles te põem em contato não te preparando. [...] A tua reação vai depender da tua base, dos teus conceitos, de como tu consegues lidar com as coisas, ou não." (Frag- mento da entrevista de a2)}

Na formação médica, ainda hoje se segue o discurso da impessoalidade e do distanciamento de fatos que cotidianamente se enfrentam nas práticas diárias: a dor, o sofrimento e, principalmente, a morte ${ }^{7}$. Muitos cursos de formação de profissionais da saúde estão carentes, em seus currículos, de disciplinas que abordem a morte, o luto e o processo de morrer, a morte no sentido de sua inexorabilidade, não como uma inimiga a vencer, mas como uma etapa da vida que necessita ser cuidada ${ }^{21}$. Os entrevistados também constatam tais dificuldades:

"Temos encontros anuais da Psiquiatria, mas é facultativo. Quem tem interesse vai. E acaba que a maioria nem pensa no assunto [...]. Aí tu te deparas com colegas ou com outras pessoas dando notícias para a família como se estivesse dizendo: 'Ah, tá com febre! Ah, morreu' [...]." (Fragmento da entrevista de a1, grifo nosso)

\section{CONCLUSÃO}

De acordo com as entrevistas realizadas e as leituras dos textos aqui citados, é possível concluir que o acadêmico de Medicina, em sua formação, aprende a se comprometer com a vida em detrimento da morte, como se esta não fizesse parte daquela. Afinal, toda a sua capacitação é para a cura, que traz gratificação do aprendizado e recompensa o esforço realizado. Quando a morte se apresenta, ela traz para o acadêmico uma sensação de frustração e um sentimento de incapacidade, pois existe um despreparo, segundo as falas dos próprios alunos, para lidar "dignamente" com a morte, já que a cura parece ser a única grande meta da Medicina. Contudo, os próprios entrevistados sabem: não se pode negar a existência da morte, sendo a preparação para enfrentá-la a melhor alternativa viável. A questão que nos colocamos, enquanto pesquisadores e docentes de futuros profissionais de saúde, é: como fazê-lo?

Os próprios entrevistados sugerem algumas alternativas quando referem que somente atividades teóricas sobre o assunto não são a solução adequada.

Talvez uma possibilidade seja abordar, durante o desenvolvimento das disciplinas teóricas e das atividades práticas, concepções menos biológicas da morte, pois, quando falamos de morte, os conceitos que chegam para o aluno de Medicina são os conceitos biológicos, mecânicos e materialistas.

As conclusões de Quintana et al. ${ }^{22}$ fazem eco a esta possibilidade, ao oferecerem outro modo de prevenir a negação das emoções como forma de defesa contra a angústia: que as disciplinas específicas da formação não se limitem a abordar os aspectos biológicos dos pacientes e incluam, também, os componentes emocionais que o contato com a doença, o sofrimento e a morte gera no estudante. Sugerem atividades de tutoria e ensino em pequenos grupos como uma forma de favorecer a emergência das emoções e a possibilidade de reflexão.

Nesta linha, propõe-se a criação de espaços de discussão nos quais as emoções decorrentes da formação possam ser compartilhadas como uma forma de minimizar as consequências de lidar todos os dias com a morte e ter um outro ser humano como objeto de estudo. Além disto, recomenda-se que algumas disciplinas enfatizem as emoções geradas no aluno em função de sua formação, não somente de forma teórica, mas por meio de observação e apresentação de casos, propiciando sua aproximação com pessoas em diferentes fases do desenvolvimento ${ }^{22}$.

A vivência da morte de um paciente suscita angústias, pois nos coloca frente a frente com a incômoda sensação de nossa finitude. Neste sentido, outra sugestão seria que tais discussões não se restringissem a apenas alguns "anos" ou a algumas disciplinas do curso.

A discussão sobre a morte, na educação formal, nas escolas de Medicina, ao longo do curso de graduação, bem como a per- 
manente atenção dispensada ao tema da morte e do limite terapêutico poderiam instituir novos comportamentos dos profissionais e dos estudantes, tornando-os mais aptos a lidar com a morte e com o paciente terminal. Se não existe vida sem morte - e, em consequência, a morte faz parte da vida dos profissionais da saúde - , ao educar o aluno para o enfrentamento da morte, estamos respeitando a integralidade do doente, do aluno e a nossa, como sujeitos de nossa vida e de nossa morte.

O conhecimento médico hoje, em geral, é tomado pelo conhecimento biológico. Contudo, é possível vislumbrar que, no futuro, o conhecimento do ser humano, das relações interpessoais e de seus sentimentos faça parte do conhecimento médico $^{23}$. As falas dos alunos entrevistados em relação à sua preparação na graduação para o enfrentamento da morte confirmam esta necessidade.

\section{REFERÊNCIAS}

1. Goldim JR. Manual de iniciação à pesquisa em saúde. Porto Alegre: Dacasa; 2000.

2. Minayo MCS. Pesquisa social. 25ํㅡㄹ ed. Petrópolis: Vozes; 2007.

3. Bardin L. Análise de conteúdo. $4^{a}$ ed. Lisboa: Edições 70; 2006.

4. Silva GSN. A construção do "ser médico" e a morte: significados e implicações para a humanização do cuidado. São Paulo; 2006. Doutorado [Tese] - Universidade de São Paulo.

5. Kovács MJ. Educação para a morte. Desafio na formação de profissionais de saúde e educação. São Paulo: Casa do Psicólogo; 2003.

6. Perazzo S. O médico e a morte. Rev Psiquiatr Clín (São Paulo). 1985;12(3):96-100.

7. Truog DR, et al. Recommendations for end-of-life care in the intensive care unit: A consensus statement by American Academy of Critical Care Medicine. Crit Care Med. 2008;36(3):953-63.

8. Quintana AM, Cecim PS, Henn CG. O preparo para lidar com a morte na formação do profissional de medicina. Rev Bras Educ Med. 2002;26(3):204-10.

9. Zaidhaft S. Morte e formação médica. Rio de Janeiro: Francisco Alves; 1990.

10. Pessini L. Distanásia: até quando investir sem agredir? Bioética. 1996;4(1):31-43.

11. Ariès P. História da morte no Ocidente. Rio de Janeiro: Ediouro; 2003.

12. Carapinheiro G. Saberes e poderes no hospital. Lisboa: Afrontamento; 1993.

13. Pitta A. Hospital dor e morte como ofício. $3^{\mathfrak{a}}$ ed. São Paulo: Hucitec; 1994.

14. Sayd JD, Oliveira JA. O ensino médico e seus implícitos sobre a morte. Rev Bras Educ Med. 1993;17(3):15-21.
15. Eizirik CL. Fantasias e realidades sobre a morte. In: Lavinsky L, org. Saúde: informações básicas. $3^{\underline{a}}$ ed rev. ampl. Porto Alegre: Ed UFRGS; 2002. p.339-45.

16. Morin E. O homem e a morte. São Paulo: Imago; 1997.

17. Diniz D. Quando a morte é um ato de cuidado: obstinação terapêutica em crianças. Cad Saúde Pública. 2006;22(8):1741-8.

18. Capena LAB. Os sentimentos dos acadêmicos de medicina no seu enfrentamento com o fenômeno da Morte. Rio Grande do Sul; 1997. Doutorado [Tese] - Pontifícia Universidade Católica do Rio Grande do Sul.

19. Novaes MRC, Trindade EM. A morte e o morrer: considerações bioéticas sobre a eutanásia e a finitude da vida no contexto da relação médico-paciente. Comum Ciênc Saúde. 2007;18(3):69-77.

20. Ceccim RB, Capozzolo AA. Educação dos profissionais da saúde e afirmação da vida: a prática clínica como resistência e criação. In: Marins JJN, Rego S, Lampert JB, Araújo JGC. Educação médica em transformação. São Paulo: Hucitec; 2004.

21. Esslinger I. De quem é a vida, afinal? São Paulo: Casa do Psicólogo; 2004.

22. Quintana AM, Rodrigues AT, Arpini DM, Bassi LA, Cecim OS, Santos MS. A angústia na formação do estudante de medicina. Rev Bras Educ Med. 2008;32(1):7-14.

23. Elias N. Solidão dos moribundos. Rio de Janeiro: J. Zahar; 2001.

\section{CONTRIBUIÇÃO DOS AUTORES}

Nára Selaimen G. Azevedo contribuiu na concepção e desenho do estudo, análise e interpretação dos dados, redação do artigo, a partir da redação de sua dissertação de Mestrado. Cristianne Famer Rocha participou da redação do artigo enviado, assim como da sua revisão, foi co-orientadora da Dissertação produzida. Paulo Roberto A. Carvalho participou da redação do artigo enviado, assim como da sua revisão, foi orientador da dissertação produzida.

\section{CONFLITO DE INTERESSES}

Declarou não haver.

\section{ENDEREÇO PARA CORRESPONDÊNCIA}

Nára Selaimen G. Azeredo

Hospital Nossa Senhora da Conceição, Unidade de Terapia Intensiva Adulto

Av. Francisco Trein, 596

Cristo Redentor - Porto Alegre

CEP 91350-200 - RS

E-mail: ns.azeredo@uol.com.br 